University of Rhode Island

DigitalCommons@URI

2019

SHORT-TERM COST-EFFECTIVENESS OF SECOND-GENERATION

LONG-ACTING INJECTABLE ANTIPSYCHOTICS AS COMPARED

WITH ORAL ANTIPSYCHOTICS IN PREVENTING

REHOSPITALIZATION OR TREATMENT SWITCH IN PATIENTS WITH SCHIZOPHRENIA

Tyler Mantaian

University of Rhode Island, tylermantaian@my.uri.edu

Follow this and additional works at: https://digitalcommons.uri.edu/theses

Recommended Citation

Mantaian, Tyler, "SHORT-TERM COST-EFFECTIVENESS OF SECOND-GENERATION LONG-ACTING

INJECTABLE ANTIPSYCHOTICS AS COMPARED WITH ORAL ANTIPSYCHOTICS IN PREVENTING

REHOSPITALIZATION OR TREATMENT SWITCH IN PATIENTS WITH SCHIZOPHRENIA" (2019). Open

Access Master's Theses. Paper 1742.

https://digitalcommons.uri.edu/theses/1742

This Thesis is brought to you for free and open access by DigitalCommons@URI. It has been accepted for inclusion in Open Access Master's Theses by an authorized administrator of DigitalCommons@URI. For more information, please contact digitalcommons-group@uri.edu. 


\section{SHORT-TERM COST-EFFECTIVENESS OF SECOND-GENERATION LONG- ACTING INJECTABLE ANTIPSYCHOTICS AS COMPARED WITH ORAL ANTIPSYCHOTICS IN PREVENTING REHOSPITALIZATION OR TREATMENT SWITCH IN PATIENTS WITH SCHIZOPHRENIA}

BY

TYLER MANTAIAN

A THESIS SUBMITTED IN PARTIAL FULFILLMENT OF THE

REQUIREMENTS FOR THE DEGREE OF

MASTER OF SCIENCE

IN

PHARMACEUTICAL SCIENCES

UNIVERSITY OF RHODE ISLAND 


\section{MASTER OF SCIENCE THESIS}

\section{$\mathrm{OF}$}

\section{TYLER MANTAIAN}

\section{APPROVED:}

Thesis Committee:

Major Professor Ami Vyas

Stephen Kogut

Andrea Paiva

Robert Dufresne

Nasser H. Zawia DEAN OF THE GRADUATE SCHOOL

UNIVERSITY OF RHODE ISLAND

2019 


\begin{abstract}
Background: Antipsychotic medications are the first-line treatment for schizophrenia. Medication non-adherence is often a problem among patients with schizophrenia, leading to relapse, rehospitalization, and high cost-burden. First-generation antipsychotics were first developed to treat schizophrenia; however, the higher risk of extra-pyramidal side effects have made them unfavorable in comparison to second-generation antipsychotics (SGA). Nevertheless, antipsychotic adherence is often suboptimal, which can lead to relapse and rehospitalization. Long-acting injectable (LAI) antipsychotics were developed to help improve adherence, thereby reducing rates of relapse. However, this drug class is associated with high treatment cost while the more common oral antipsychotics are inexpensive in comparison.
\end{abstract}

Methods: Data from Optum’s de-identified Clinformatics ${ }^{\circledR}$ Data Mart Database from years 2010-2015, was utilized to conduct a retrospective cohort study and costeffectiveness analysis comparing the outcomes and cost of LAI second-generation antipsychotics (SGAs) with oral SGAs for the treatment of schizophrenia. Patients with a history of at least two inpatient hospitalizations for schizophrenia two years prior to a recent relapse hospitalization (index date) during 2012-2014 were identified. Patients were required to have a claim for a LAI SGA or oral SGA within 40 days of discharge from the index hospitalization. Patients were entered into a 12-month follow-up period during which medication cost, adherence, and medication switch or rehospitalization due to relapse were measured. A patient level descriptive analysis was conducted followed by developing a decision model for which an incremental cost-effectiveness ratio (ICER) was estimated comparing incremental cost of treatments and incremental effectiveness. 
Results: 158 patients met the study's inclusion-exclusion criteria. Of 158 patients, 135 (85.4\%) had a claim for an oral SGA within 40 days of index discharge and $23(14.6 \%)$ had a claim for a LAI SGA. The mean age of the population was 48-years (standard deviation, $\mathrm{SD} \pm 12.0)$ with similar distribution observed in gender ( $49.4 \%$ female) Patients experienced about 4 hospitalizations $(S D \pm 2.7)$ on average, prior to their index date and also had a mean index length of stay of about 10 days $(\mathrm{SD} \pm 8.8)$. Compared to patients receiving oral SGAs, patients receiving LAIs experienced numerically higher adherence rates, numerically higher proportion of stable patients, and higher mean cost of medication $(\$ 1,339.20$ vs. $\$ 282.90, \mathrm{p}<.0001)$. A sensitivity analysis determined that change in the proportion of adherent patients prescribed LAIs had a large impact on the ICER value.

Conclusion: Although statistically not significant, the LAI cohort was associated with numerically lower rates of switch or rehospitalization and a higher proportion of adherent patients compared to oral SGAs. While LAIs are associated with a much higher average monthly cost than their oral comparators, the decision analysis indicated that the additional expenditure was associated with improvement in the measured outcome. Further research is warranted examining populations with higher prevalence of schizophrenia to provide larger sample sizes and to measure cost-benefit, which may illustrate cost-avoidance through the cost of rehospitalization due to relapse. 


\section{ACKNOWLEDGMENTS}

I would like to express my appreciation and gratitude to my major professor, Dr. Vyas. Her mentorship and dedication to helping me complete my thesis, course work, and projects was instrumental in completing my academic career at URI. I have obtained countless skills as a direct result of her guidance, that will continue to aid me throughout my career as a pharmacoeconomic and pharmacoepidemiologic researcher.

I would also like to thank Dr. Kogut, for I would not be a graduate of the Health Outcomes program if it were not for his recommendation while I was an undergraduate. His unique knowledge of pharmacoeconomic methods has been invaluable for the completion of my thesis.

In addition to my professors, I would like to thank my committee members Dr. Paiva and Dr. Dufresne. Their expert-level counsel allowed me to have a strong foundation and formulate sound methods from proposal to final draft.

Finally, I would like to thank my family for encouraging me to pursue a higher education and follow my ambitions. They were there every step of the way. 


\section{TABLE OF CONTENTS}

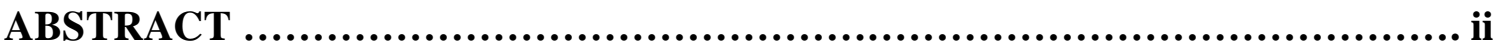

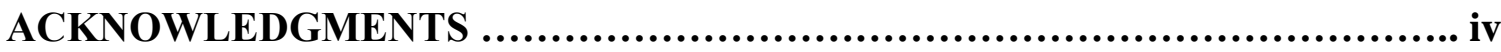

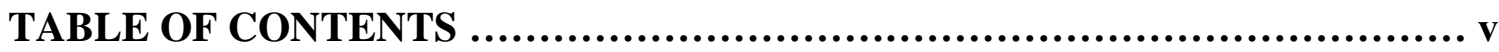

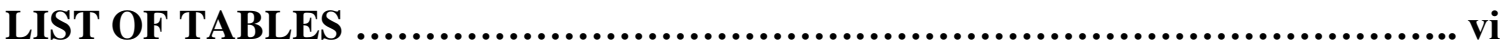

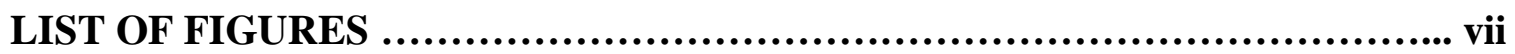

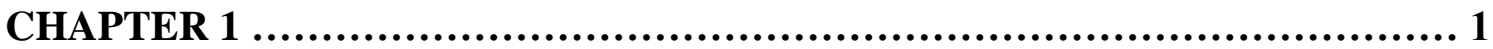

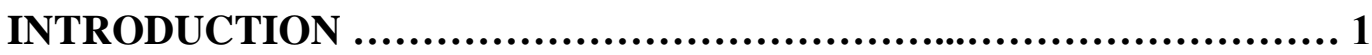

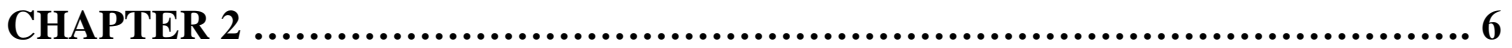

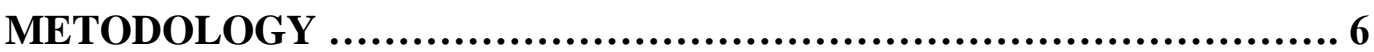

CHAPTER 3 ....................................................................... 11

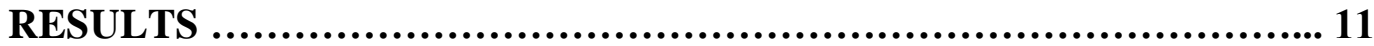

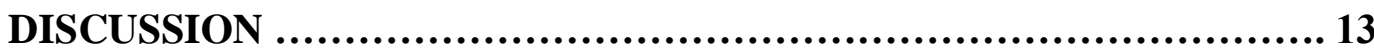

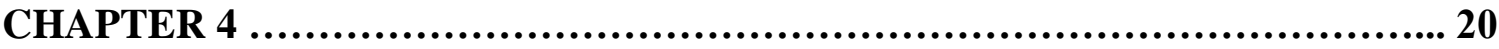

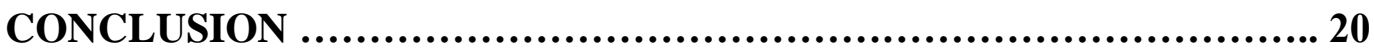

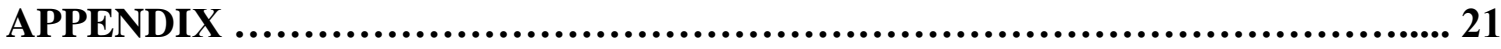

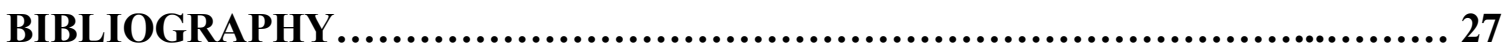




\section{LIST OF TABLES}

Table 1. Baseline demographics of patients with schizophrenia ..................... 21

Table 2. Results: Adherence, stability, medication switch, and relapse .............. 22

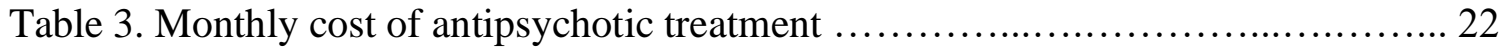

Supplemental Table 1. Currently available LAI atypical antipsychotics ............... 23 


\section{LIST OF FIGURES}

Figure 1. Study sample selection flow chart ...................................... 24

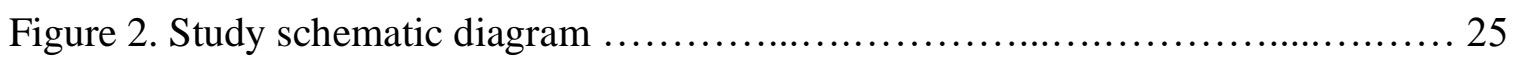

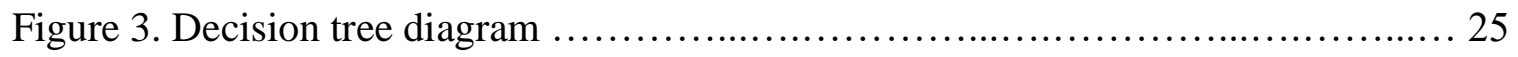

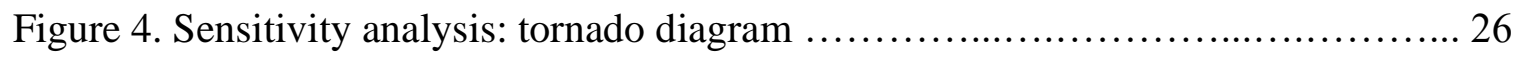

Figure 5. One-way sensitivity analysis: LAI adherence.......................... 26 


\section{CHAPTER 1}

\section{INTRODUCTION}

Schizophrenia is a lifelong, incurable, mental disorder that affects about $1 \%$ of the United States' population.1 Schizophrenia typically develops in late adolescence to young adulthood and tends to occur earlier in males than in females.1 Patients with schizophrenia may experience "positive" symptoms including delusions, hallucinations and cognitive dysfunction as well as "negative" symptoms such as reduced expression and motivation.1 Such symptoms often put patients out of touch with reality and lower their mental awareness. Many patients turn to substance abuse as means to cope and selfmedicate. Patients with schizophrenia have about five times higher rate of tobacco smoking than that found in the general population 2 and have higher prevalence of illicit drug use.3 Patients also live with a 5\% suicide risk1 and are twelve times as likely to die from suicide compared with the general world population. 4 Because of these factors and disease exacerbations, schizophrenia is associated with an increased mortality rates and a decrease in life expectancy of about 14.5 years compared to the average world population.6

Antipsychotic medications are used as first-line treatment for schizophrenia in order to manage and control disease symptoms. There are first-generation (typical) and second-generation (atypical) antipsychotics. First-generation antipsychotics (FGAs), such as haloperidol or fluphenazine, are directly associated with extrapyramidal side effects such as tardive dyskinesia, drug induced parkinsonism and dystonias.7-9 Secondgeneration antipsychotics (SGAs) have a decreased risk of extrapyramidal side effects 
and hence may be preferred by patients. SGAs are also prescribed more frequently than first-generation antipsychotics.10

Schizophrenia is a mental illness frequently seen in hospitals across the country. In 2010, schizophrenia was the second most hospitalized mental illness 11 and in 2014, the second most common hospital visit among any inpatient stay occurring in 18-44 years age group (excluding maternal or neonatal principal diagnoses).12 Due to frequent hospitalizations, schizophrenia can cause substantial burden to the US healthcare system.13,14 Due to the severity of the disease, relapses are common in patients with schizophrenia. Patients who relapse are associated with high hospitalization rates and cost 15 and patients with a history of relapse are associated with an even higher cost burden than those who do not experience relapses. 16

Relapse rates are often influenced by medication adherence, 17 with low medication adherence being the leading cause of relapse in psychosis.18 Despite the direct correlation between relapse and non-adherence, adherence rates among patients with schizophrenia are often suboptimal.19-21 In order to address the difficulties in adhering to oral therapies and provide better outcomes, long-acting injectable antipsychotics (LAIs) were developed as an intra-muscular depot injection given by a clinician or pharmacist. Each dose can provide two-weeks to one-months' worth of medication or more, potentially substituting 30 or more pills with one injection. LAIs are intended increase adherence and therefore decrease the potential of relapse and hospitalization. The first LAI SGA was approved in 2003, and these formulations increasingly began to become recognized for their usefulness in chronic patients.22 With additional LAIs being developed throughout the years, LAIs demonstrated their effectiveness in reducing 
relapse rates and increasing patient adherence.23-26 However, the high cost of newer LAIs may prevent patients from receiving this beneficial treatment.27

Several cost-effectiveness studies have been conducted comparing LAIs to oral antipsychotics. One non-US study conducted in Portugal compared the costs and effectiveness of oral olanzapine to LAI risperidone, paliperidone, and haloperidol.25 A decision model with adherence rates were utilized with a one-year timeframe. Outcomes of inpatient hospitalization due to relapse, emergency room admission, and stability were assessed. The authors reported that patients utilizing LAI paliperidone had a lower rate of relapse or emergency room admission and a higher cost than oral olanzapine. Although comprehensive, their study poses limitations that can be improved upon. As such this was a non-US study, therefore findings cannot be applied to the US population and US payers. The authors state that the model inputs used were based on various pieces of literature and clinical trials, this in return may limit its real-world applicability as data is not taken from a population sample or database.

A Medicaid-based study analyzed the cost-effectiveness of paliperidone LAI to oral antipsychotics.28 The model utilized a decision model and was used to inform outcomes in stable patients over a 12-month period. The authors found that paliperidone LAI was associated with higher adherence and was projected to decrease psychiatric hospitalizations compared to oral antipsychotics. The authors state that paliperidone LAI substantially decreases costs over an 18-month period. However, the cost of medication was not incorporated into the model, instead the findings are reported with the potential cost prevented by implementing LAIs in comparison to oral antipsychotics. Data from this study was also obtained from three separate clinical trials, which may not represent a 
real-world sample as patients are subject to strict inclusion and exclusion criteria and are often observed for a limited period of time. Two of the trials were also conducted globally and were subject to very different designs, according to the authors.

Another cost-effectiveness study that compared LAIs to an oral antipsychotic was a decision model comparing LAI olanzapine to LAI risperidone, LAI paliperidone, LAI haloperidol, and oral olanzapine.26 The model was developed with a one-year time horizon, analyzing adherence rates and probability of relapse. LAI olanzapine was associated with lower inpatient and outpatient relapses and higher proportion of stable patients. LAI olanzapine had lower cost and better outcomes when compared to the other LAIs measured, however, oral olanzapine was associated with poorer outcomes but a lower cost. Similar to the Portugal study, the authors utilized literature and expert opinion to determine model inputs. The study also measured medication adherence as an initial characteristic of patients starting therapy, not accounting for possible changes in adherence throughout the model.

Our study sought to improve upon the limitations of previous cost-effectiveness studies by analyzing LAIs and oral antipsychotics using claims data from a large commercial insurer in the US. Patients with schizophrenia are representative of a realworld sample and model inputs are directly derived from an administrative claims database, limiting the potential of bias associated with obtaining model inputs from within the literature, as inputs are often derived from multiple sources and different study samples. Utilizing a retrospective database also allows for continuous measurement of recurring variables, such as adherence, within a defined follow-up period. This study is also not industry funded, which excludes the potential of conflict of interest. 
The objective of this study was to evaluate the cost-effectiveness of LAI antipsychotics, specifically atypical antipsychotics, as an alternative to oral SGAs in the prevention of rehospitalization due to relapse or medication switch, for the treatment of schizophrenia from a third-party payer perspective. 


\section{CHAPTER 2}

\section{METHODS}

\section{Study Design \& Data Source}

A pharmacoeconomic analysis was conducted using data from a retrospective claims US-based database, in order to describe the utilization and cost-effectiveness of oral and LAI second-generation antipsychotic medications among patients with schizophrenia.

Optum commercial claims database was utilized to complete this study. Optum's deidentified Clinformatics $\circledast$ Data Mart Database29 is an administrative healthcare claims database for members of a national managed care commercial health insurer. Optum includes pharmacy claims, medical claims, lab results, standard pricing, member demographic, and inpatient confinement data. Inpatient claims are coded utilizing International Classification of Disease, 9th and 10th Revision, Clinical Modification (ICD9-CM, ICD-10-CM). Medical claims are coded with ICD-9, ICD-10, and Healthcare Common Procedure Coding System (HCPCS) codes. Pharmacy claims use the National Drug Code (NDC) coding system for prescription drug claims. All records and claims within the database are de-identified. This study utilized data from years 2010-2015.

\section{Study Population}

The study population consisted of patients with an inpatient claim of a primary diagnosis of schizophrenia (ICD-9 295*) identified during the years 1/1/201211/21/2014. The most recent hospitalization during the timeframe was labeled as a patient's "index hospitalization." In addition, patients were also required to be continuously enrolled for at least two years before and one year and 40 days after the 
index date. The exposure period was defined as any patient prescribed a LAI SGA or oral SGA within 40-days after discharge from their index hospitalization within the index period of $1 / 1 / 2012-11 / 21 / 2014$. Patients not within the age range of 18 to 64 -years on their index date were excluded from this study as well as patients with a LAI SGA claim prior to their index date. Patients with extensive inpatient care, defined as over 60-day length of stay, as their index hospitalization were excluded as the service provided to these outlier patients would likely be relatively distinct from the rest of the population. 30 Figure 1 depicts the patient flow chart with the inclusion and exclusion criteria, while Figure 2 depicts the study schematic diagram. Patients prescribed a LAI or oral dosage form of the LAI SGAs listed in Supplemental Table 1 were included in the study.

Patients were categorized into two cohorts, oral SGA or LAI SGA based upon their drug claim during the exposure period.

\section{Study Measures}

The endpoints in this analysis were rehospitalization due to relapse, switching from exposure medication without rehospitalization due to relapse, or completion of the 405-day follow-up period without switch or rehospitalization. Rehospitalization due to relapse was defined by any hospitalization within 405 days from a patient's index date with a primary diagnosis of schizophrenia (ICD-9 $295^{*}$ or ICD-10 F20*, F25*). The follow-up for these patients ended on their date of rehospitalization. Switching medications was considered to be lack of effectiveness or tolerability provided by the exposure drug. This was defined as a patient discontinuing their exposure medication for at least 60 days after the remainder of available supply from the last exposure drug fill date.31,32 The follow-up for patients who switched medications concluded on the first 
claim of any non-exposure antipsychotic after exhausting the remaining supply of their exposure antipsychotic. Patients with a 60-day gap but failing to have a claim for a nonexposure antipsychotic before the end of follow-up were not considered to switch, the days without an antipsychotic medication contributed to the patient's adherence rate.

Upon rehospitalization, switch, or completion of follow-up, adherence rates were calculated. Adherence rates were calculated using medication possession ratios (MPR) and is only representative of adherence to the exposure drug. MPR was calculated as the ratio of the total number of nonoverlapped days covered by antipsychotics during the follow-up period, over the total days until relapse from index hospitalization, switch, or end of follow-up (405 days).33 Rehospitalization due to relapse was the primary outcome assessed in this study and was measured prior to switching medications. However, if a patient were to switch treatments before relapse, their adherence rates were calculated until switch. Adherence was categorized using MPR thresholds of $\geq 0.8$ and $<0.8$. Acceptable adherence has been defined by others as an MPR ratio of 0.8 or above, with poor adherence below $0.8 .18,19$

\section{Cost of Medications}

Optum data includes a "standard price" as the cost of a claim, which represents the total amount paid by the insurer plus the amount paid by the patient for a medication, procedure, medical visit, inpatient stay or other healthcare service. Patient copays, deductibles, and dispense fees were subtracted out from the standard price to obtain the medication cost incurred by the third-party payer. Patients with schizophrenia may be coprescribed multiple types of antipsychotic medication along with their exposure medication, therefore, the medication cost calculated in this study is reflective of any 
antipsychotic use during the follow-up period. LAI administration costs were included in the treatment costs as well. Cost was calculated by dividing total cost of medication by total follow-up days. Costs for patients with a 60-day medication gap without another antipsychotic claim during follow-up were measured until the date of their last exposuredrug claim plus the remaining days' supply. Cost was multiplied by 30 days to present a monthly figure.

Gender, age, region, insurance status, health plan type, number of prior hospitalizations, and index hospitalization length of stay were utilized as covariates for this analysis.

\section{Statistical Analyses}

A patient level descriptive analysis was conducted to evaluate the differences in baseline characteristics between the LAI and oral antipsychotic cohorts (Table 1). Rates of adherence and medication switching were measured and compared. The mean cost of medication, days of follow-up, age, number of prior hospitalizations, and the index hospitalization length of stay was calculated and compared between the two study cohorts using chi-squared and t-tests. The mean cost of medication between the two cohorts were compared as log-transformed costs and analyzed utilizing a t-test for independent samples.

A decision tree was developed to determine the cost-effectiveness of LAI versus oral therapy accounting for patient adherence rates (Figure 3). Branches were constructed as the proportion of patients that were adherent or non-adherent per cohort. The probability of adherent or non-adherent patients remaining stable in follow-up (no rehospitalization or medication switch) was applied. A third-party payer perspective and 
one-year time-horizon were utilized. The decision tree was modeled and analyzed using TreeAge Pro 2019, R1@.34

\section{Study Outcomes}

The decision analysis defined a combined outcome representing a "stable" patient as having no rehospitalization due to relapse or switching of treatment during the followup period. This outcome was evaluated according to level of medication adherence using MPR and across treatment cohorts listed in Table 2.

Establishing which treatment type was more cost-effective was calculated through an incremental cost-effectiveness ratio (ICER). The numerator of the ICER value represented the difference in mean cost of medication and the denominator represented the difference in exposure drug effectiveness (percentage of patients who neither switched regimen nor experienced a rehospitalization due to relapse, i.e. stable patients).

A deterministic sensitivity analysis was conducted using TreeAge Pro 2019, R1๑.34 A tornado diagram was developed to address uncertainty within the model. The analysis illustrates variations in the input parameters that affect the calculated ICER value such as increasing the proportion of adherent patients receiving LAIs to $100 \%$ and decreasing proportion of adherent patients receiving oral SGAs to 0\%. All drug cost inputs for both LAI and oral treatment groups were adjusted by $50 \%$. 


\section{CHAPTER 3}

\section{RESULTS}

A total of 5,312 patients with schizophrenia were identified during the index period. After applying the pre-index, follow-up and age criteria, 631 patients were identified; 291 patients were excluded who did not have a pharmacy dispensing for an SGA or LAI SGA during the 40-day exposure period following discharge from the index hospitalization, 157 patients were excluded who received a LAI SGA prescription before their index hospitalization or who were deemed to have extensive inpatient use. An additional 25 patients who received oral aripiprazole as an exposure drug or switched to LAI after the exposure period, were removed. Only patients with an oral medication for which a LAI form was available were included and because no patients in the LAI cohort received aripiprazole, these patients were excluded. The final population included 158 patients (Figure 1).

\section{Descriptive analysis}

The mean age of the study population upon index hospitalization was 48-years (standard deviation, SD \pm 12.0$)$ with similar distribution observed in gender $(49.4 \%$ female). The majority of patients were covered by Medicare (81.7\%) and were located in the Midwest or South regions (69.0\%) of the US. Patients experienced about 4 hospitalizations $(\mathrm{SD} \pm 2.7)$ on average, prior to their index date and had a mean index length of stay of about 10 days ( $\mathrm{SD} \pm 8.8$ ) (Table 1).

A total of $135(85.4 \%)$ patients were classified to the oral antipsychotic cohort and $23(14.6 \%)$ patients to the LAI cohort. Age distribution was similar in both cohorts, with an average age of 48.5 years $(S D \pm 12.4)$ for patients in the oral antipsychotic cohort 
and 48.4 years $(S D \pm 10.0)$ for patients in the LAI cohort $(\mathrm{p}=0.94)$. Patients in the LAI cohort were more likely to be male than those in the oral antipsychotic cohort. Distributions of mean index length of stay ( 9.9 vs. 9.5 days, $\mathrm{p}=0.82$ ) and mean prior hospitalizations (3.2 vs. 3.7 days, $\mathrm{p}=0.23$ ) were similar between the LAI and oral cohorts, respectively. Patients in the oral antipsychotic cohort had about 310 days (SD \pm 127.3 ) of follow-up on average, compared with an average of 299 days (SD \pm 135.3 ) for the LAI cohort $(\mathrm{p}=0.69)$.

\section{Outcomes}

Of the 135 patients receiving oral antipsychotics, $67(49.6 \%)$ were prescribed risperidone and 61 were prescribed $(45.2 \%)$ olanzapine during the exposure period. The other 23 patients all received a LAI SGA.

Compared to patients receiving oral antipsychotics, patients receiving LAIs experienced a higher proportion of adherent patients and higher proportion of stable patients, although these differences were not statistically significant. Patients receiving LAIs had a higher mean monthly cost of medication $(\$ 1339.20$ vs. $\$ 282.90, \mathrm{p}<.0001)$. The statistical comparison for costs involved log transformed values as the skewness and kurtosis values for non-transformed costs were relatively high (LAI: 3.46, 12.46 ; PO: 2.11, 4.21, respectively). Skewness and kurtosis for log-transformed values were calculated at 2.93 and 9.57 for LAI costs and 0.26 and -0.92 for oral costs, respectively. Adherence and cost figures are presented in Table 2 and Table 3.

The decision tree captured costs for patients according to a level of adherence and the combined endpoint of medication switch or rehospitalization, as compared with not experiencing either of these outcomes (i.e. remaining stable) during follow-up. The 
branch probabilities and costs are shown in the decision tree in Figure 3. The mean costs for the oral and LAI cohorts after implementing adherence and state probabilities, were estimated to be $\$ 259.91$ and $\$ 1322.04$, respectively.

\section{Sensitivity Analysis}

A deterministic sensitivity analysis was conducted to address uncertainty within the developed decision tree model. Adherence and cost inputs were modified to illustrate changes in the ICER value. Figure 4 addresses multiple variations on the range of the base-values in the decision model that would make the ICER value more or less favorable for LAIs. The diagram included increased LAI adherence (proportion of adherent patients increased to $100 \%$ ), decreased oral adherence (proportion of adherent patients decreased to $0 \%$ ), and a $50 \%$ decrease and increase to all treatment costs. The sensitivity analysis suggests that a minor increase in the proportion of adherent patients receiving LAIs, leads to a lower ICER value and improved treatment value.

\section{Discussion}

This study applied a retrospective cohort analysis using a real-world sample obtained from Optum’s de-identified Clinformatics ${ }^{\circledR}$ Data Mart Database 29 to examine the cost and outcomes of two different medication classes, oral SGAs and LAI SGAs, in patients with schizophrenia. Patients with a history of inpatient hospitalizations were the primary focus of this study as LAIs have often been intended for patients that have more severe forms of schizophrenia or patients with a history of relapse and non-adherence. 35 Therefore, we required that all patients were required to have at least two inpatient hospitalizations for schizophrenia prior to their index hospitalization. Although guidance 
is limited on this criterion of two or more prior hospitalizations, it was necessary to help narrow the cohort to patients who are more likely to be prescribed LAIs and achieve a disease severity that was similar between the oral and LAI treatment groups. Despite the large population for study provided by the data source, after the application of our inclusion criteria only a small number of cases remained for our analysis. This necessitated the combining of the study outcomes of rehospitalization and medication switch into a composite outcome, and also diminished statistical power when evaluating between-group differences.

The ICER value was calculated through the decision tree to incorporate the impact of medication adherence and to assess the incremental cost required for an additional outcome of interest associated with the use of LAIs over oral SGAs. According to the Institute for Clinical and Economic Review, an ICER ratio often uses quality adjusted life years (QALY) as the measure of effectiveness (denominator) to assess value.36 However, our study did not aim to measure long-term survival or impact on patient quality of life, and thus QALY was not measured. The denominator of the ICER ratio in our study was representative of the numerical difference in the proportion of stable patients between the LAI and oral treatment groups. Willingness to pay (WTP) thresholds are often used when calculating ICER values to determine if a treatment is a cost-effective alternative to the comparative treatment. The Institute for Clinical and Economic Review recommends US based studies use WTP thresholds of $\$ 50,000$ $\$ 150,000$ per QALY to guide considerations for the value of the alternative treatment option.36 However, other similar studies have reported ICER results using QALY as the 
outcome measure, $25,26,40$ and we were unable to find any published data describing thresholds for willingness to pay for treatment stability in schizophrenia.

Interpreting ICER values between studies can be difficult due to variation in how cost and effectiveness inputs are derived. Previous studies have demonstrated estimated ICERs of about $\$ 14,500 / \mathrm{QALY}$ and $\$ 26,800 / \mathrm{QALY}$ (to their respective study years) when comparing LAIs to oral SGAs.25,26 However, QALY was utilized as an effectiveness measure and drug treatment costs were combined with inpatient, outpatient, and rehabilitation clinic costs. Therefore, a direct comparison of ICER values may not be accurate. While our study did not incorporate non-pharmacological treatment costs, we did measure all antipsychotic use to represent an average monthly cost categorized under the exposure medication sub-groups. One US-based study analyzed the antipsychotic medication costs of LAI risperidone and oral SGAs in a clinical trial in 2009. The cost of LAI risperidone including other antipsychotic medications was estimated to be over $\$ 1900$ per quarter for an estimated monthly cost of approximately $\$ 650$. Oral SGAs including other antipsychotic medications was estimated to be $\$ 1150$ or approximately \$380 per month.37 Although this study illustrates just under a twofold increase in cost when comparing LAI risperidone and oral SGAs, our study suggests that LAI risperidone and other LAI SGAs are associated with an even higher cost when compared to oral agents.

Adherence can be measured in a number of ways. As discussed, we utilized MPR to assess adherence in our study. Mean adherence was not calculated, instead patients were classified into adherent $(\geq 0.80)$ or nonadherent $(<0.80)$ categories based on their individual MPR in the follow-up period. While this does not represent the exact 
adherence rate a patient may experience with a LAI SGA or oral SGA, dichotomizing the adherence measure is a common approach in the literature. Moreover, classifying adherence in categories allows for the calculated proportions to be analyzed within a decision tree. This is a common method when incorporating adherence into a costeffectiveness analysis with a decision model, as prior studies suggest.25,26,40

Switching antipsychotic treatment is common among patients with schizophrenia. The Clinical Antipsychotic Trials of Intervention Effectiveness (CATIE) study, a large multi-site, nationwide, trial, assessed the effectiveness of oral antipsychotic medication in 1,493 patients with chronic schizophrenia.38 It was found that on average, $74 \%$ of the study population discontinued the study medication within 18-months due to efficacy or intolerability. In our study, $29 \%$ of patients discontinued their exposure antipsychotic medication and started on another non-exposure antipsychotic and about $15 \%$ discontinued their exposure medication but did not start another antipsychotic medication (not classified as switch). While these rates cannot be directly compared to results from the CATIE study due to differences in follow up time, study population, and other factors, our results nevertheless corroborate that a substantial proportion of patients do not persist with the prescribed medication.

A deterministic sensitivity analysis was conducted to assess uncertainty within the decision model (Figure 4). It was determined that any change in the proportion of adherent patients has a large impact on the ICER, specifically the proportion of patients adherent to LAIs. Due to the small numerical difference in incremental effectiveness at base-case inputs, the value becomes highly sensitive to any change in a path probability. 
To better illustrate the change in the ICER value by LAI adherence, a one-way sensitivity analysis of the proportion of adherent patients receiving LAIs was conducted (Figure 5).

In spite of the established clinical benefits LAIs offer to patients with schizophrenia, this class of antipsychotics is still prescribed much less frequently than their oral comparators. Only about $15 \%(\mathrm{n}=23)$ of the study population was prescribed LAIs in our study. One recent claims-based study that utilized Truven Health Analytics MarketScan Medicaid data from 2010-2013, measured the outcomes of LAIs compared to oral antipsychotics in patients with schizophrenia. Patients were required to have a recent (6-month) history of non-adherence. Out of about 4,000 patients that met inclusion criteria, the researchers identified 340 users of a LAI antipsychotic (about 9\%) within 30 days of their index hospitalization. Of those patients, only 183 patients (about 5\%) were prescribed a LAI SGA (risperidone or paliperidone).32 Another claims-based study assessing the effectiveness of LAIs in comparison to oral agents found that about $15 \%$ of LAI naïve patients were initiated on any LAI with about 7\% initiating a LAI SGA.39 Future studies are warranted that explore the boundaries around the accessibility and prescribing inclinations of LAIs, specifically LAI SGAs.

\section{Limitations}

This study has multiple limitations that warrant discussion. Due to the retrospective and observational nature of this study, it is subject to selection bias. This was mitigated through detailed inclusion and exclusion criteria that yielded two similar cohorts. Adherence was limited to the information provided with the pharmacy claims data and is only representative of the exposure medication. Patients with gaps in their 
exposure drug claims were assumed to be non-adherent. Data describing medication use and treatment during inpatient visits were not available with the data source used.

The sample size of our study was relatively small, which therefore diminishes statistical power when evaluating differences between the two treatment groups. We were also unable to identify any patients that received LAIs administered in outpatient clinics. HCPCs codes were utilized in addition to NDC codes to account for such patients, however, this did not yield additional patients. Despite a small sample size, the rate of which patients are prescribed LAIs is accurate and comparable to previous US claimsbased studies.32,39 To detect a statistically significant difference between the effectiveness values of both treatment cohorts measured in our study, it is suggested that the population size of the LAI and oral cohorts be approximately 2,500 and 14,700 patients, respectively.

Cost of treatment can be difficult to capture when measuring adherence, as patients who are nonadherent will have lower costs than those who are not. To attempt to control for this issue, patients without an exposure drug claim 60 days after their last days' supply were identified and their costs were measured from the first claim of the exposure drug to the last claim of the exposure drug. However, patients with smaller gaps between exposure medication fills were not accounted for when measuring cost. Average monthly cost is also representative of any antipsychotic use as many patients with schizophrenia received multiple antipsychotic medications on a monthly basis. Patients prescribed LAIs also typically receive the oral dosage form of the drug along with their injectable, which is an added cost that needed to be captured. Costs are presented in their respected years of payment, as they were not adjusted for inflation. 
This study also does not include aripiprazole LAI as it was approved by the US Food and Drug Administration in 2013.41 Patients are more likely to be prescribed other LAI SGAs that were available before the release of aripiprazole LAI (paliperidone, olanzapine, or risperidone) as many patients' index discharge dates were around the time of approval. Patients with an exposure drug claim for oral aripiprazole were removed to make the two cohorts more comparable.

Lastly, this model is limited to a one-year timeframe, however, incorporating a longer timeframe is challenging given the disease pathway and a higher rate of patients switching their medication is likely to occur.38 This makes it furthermore challenging to measure outcomes over a longer time period. However, a one-year follow-up period is common in cost-effectiveness studies for evaluating the short-term outcomes of newly initiated LAI antipsychotic therapy.25,26,35,40

Despite these limitations, we believe that this is the first cost-effectiveness analysis comparing LAI SGAs to oral SGAs with Optum data. Providing insights into both public and commercially insured patients, as a contrast with only publicly insured patients, which comprises much of the extant literature. 


\section{CHAPTER 4}

\section{CONCLUSION}

This study offers real-world evidence for the use of LAI SGAs. Although statistically not significant, the LAI cohort was associated with numerically lower rates of switch or rehospitalization and a higher proportion of adherent patients compared to oral SGAs. Although LAIs are associated with a much higher average monthly cost than their oral comparators, their intended benefit to prevent medication switch or relapse was modeled in our study. However, due to the small sample size and statistically nonsignificant results, these findings may not be sufficiently precise. We recommend that our findings not be used for policy decisions. Further research is warranted with a larger sample size and in terms of cost-benefit, which can illustrate cost-avoidance through the cost of rehospitalization due to relapse. With the potential for further expansion of new agents in the LAI antipsychotic class, generic drug development, and increased awareness of the benefits provided by LAIs, treating a chronic mental illness like schizophrenia, will become more efficient and less expensive. 


\section{APPENDIX}

Table 1. Baseline demographics of patients with schizophrenia $\left({ }^{*}\right.$ Cell counts $\left.<11\right)$

\begin{tabular}{|c|c|c|c|c|c|c|c|}
\hline & \multicolumn{2}{|c|}{ Total $(n=158)$} & \multicolumn{2}{|c|}{$\mathrm{PO}(\mathrm{n}=135)$} & \multicolumn{2}{|c|}{ LAI (n=23) } & \multirow{2}{*}{$\begin{array}{c}\text { PO vs. LAI } \\
\text { p Value }\end{array}$} \\
\hline & $\mathrm{n}$ & $\%$ & $\mathrm{n}$ & $\%$ & $\mathrm{n}$ & $\%$ & \\
\hline \multicolumn{8}{|l|}{ Age at index, years } \\
\hline $18-39$ & 33 & 20.89 & 28 & 20.74 & $*$ & $*$ & \\
\hline $40-49$ & 39 & 24.68 & 31 & 22.96 & $*$ & $*$ & \\
\hline $50-59$ & 57 & 36.08 & 50 & 37.04 & $*$ & $*$ & \\
\hline $60 \leq$ & 29 & 18.35 & 26 & 19.26 & $*$ & $*$ & \\
\hline \multicolumn{8}{|l|}{ Gender } \\
\hline Male & 80 & 50.63 & 67 & 49.63 & $*$ & $*$ & \\
\hline Female & 78 & 49.37 & 68 & 50.37 & $*$ & $*$ & \\
\hline \multicolumn{8}{|l|}{ Region } \\
\hline Northeast & 18 & 11.39 & 15 & 11.11 & $*$ & $*$ & \\
\hline Midwest & 47 & 29.75 & 40 & 29.63 & $*$ & $*$ & \\
\hline South & 62 & 39.24 & 56 & 41.48 & $*$ & $*$ & \\
\hline West & 31 & 19.62 & 24 & 17.78 & $*$ & $*$ & \\
\hline \multicolumn{8}{|l|}{ Insurance } \\
\hline Medicare & 129 & 81.65 & 108 & 80.00 & $*$ & $*$ & \\
\hline Commercial & 29 & 18.35 & 27 & 20.00 & $*$ & $*$ & \\
\hline \multicolumn{8}{|l|}{ Product } \\
\hline Health Maintenance Org. & 76 & 48.10 & 66 & 48.89 & $*$ & $*$ & \\
\hline Other & 82 & 51.90 & 69 & 51.11 & $*$ & $*$ & \\
\hline \multicolumn{8}{|l|}{ Prior Hospitalizations } \\
\hline 2 & 67 & 42.41 & 57 & 42.22 & $*$ & $*$ & \\
\hline $3-5$ & 73 & 46.20 & 63 & 46.67 & $*$ & $*$ & \\
\hline $5<$ & 18 & 11.39 & 15 & 11.11 & $*$ & $*$ & \\
\hline \multicolumn{8}{|l|}{ Index length of stay, days } \\
\hline $1-5$ & 56 & 35.44 & 52 & 38.52 & $*$ & $*$ & \\
\hline $6-10$ & 50 & 31.65 & 45 & 33.33 & $*$ & $*$ & \\
\hline \multirow[t]{3}{*}{$10<$} & 52 & 32.91 & 38 & 28.15 & $*$ & $*$ & \\
\hline & \multicolumn{2}{|c|}{ Total $(n=158)$} & \multicolumn{2}{|c|}{$\mathrm{PO}(\mathrm{n}=135)$} & \multicolumn{2}{|c|}{ LAI $(n=23)$} & \\
\hline & Mean & Std Dev & Mean & Std Dev & Mean & Std Dev & \\
\hline Age at index, years & 48.4 & 11.96 & 48.54 & 12.4 & 48.35 & 9.97 & 0.94 \\
\hline Prior Hospitalizations & 3.63 & 2.74 & 3.70 & 2.90 & 3.22 & 1.44 & 0.23 \\
\hline Index length of stay, days & 9.53 & 8.75 & 9.50 & 9.10 & 9.91 & 6.58 & 0.82 \\
\hline Follow-up, days & 308.57 & 128.12 & 310.24 & 127.32 & 298.83 & 135.25 & 0.69 \\
\hline Switch & 175.57 & 115.61 & 184.32 & 119.54 & $*$ & $*$ & \\
\hline Relapse & 223.25 & 128.53 & 220.11 & 131.26 & $*$ & $*$ & \\
\hline
\end{tabular}




\begin{tabular}{|c|c|c|c|c|c|c|c|c|}
\hline \multirow{7}{*}{$\begin{array}{l}\text { Total } \\
\text { Stable } \\
\text { Switch } \\
\text { Relapse }\end{array}$} & \multicolumn{4}{|c|}{$\mathrm{PO}(\mathrm{n}=135)$} & \multicolumn{4}{|c|}{ LAI $(n=23)$} \\
\hline & \multicolumn{2}{|c|}{$\geq 0.80$} & \multicolumn{2}{|c|}{$<0.80$} & \multicolumn{2}{|c|}{$\geq 0.80$} & \multicolumn{2}{|c|}{$<0.80$} \\
\hline & $\mathrm{n}$ & $\%$ & $\mathrm{n}$ & $\%$ & $\mathrm{n}$ & $\%$ & $\mathrm{n}$ & $\%$ \\
\hline & 81 & 60.00 & 54 & 40.00 & * & * & * & $*$ \\
\hline & 53 & 67.95 & 25 & 32.05 & $*$ & * & * & * \\
\hline & 19 & 50.00 & 19 & 50.00 & $*$ & $*$ & * & * \\
\hline & $*$ & * & $*$ & $*$ & $*$ & * & $*$ & $*$ \\
\hline
\end{tabular}

Table 3. Monthly cost of antipsychotic treatment, $\$(*$ Cell counts $<11)\left({ }^{\wedge} \log\right.$ transformed $)$

\begin{tabular}{|c|c|c|c|c|c|}
\hline & \multicolumn{2}{|c|}{$\mathrm{PO}(\mathrm{n}=135)$} & \multicolumn{2}{|c|}{ LAI $(n=23)$} & $\mathrm{PO}$ vs. $\mathrm{LAI}^{\wedge}$ \\
\hline & Mean & Std Dev & Mean & Std Dev & $\mathrm{p}$ Value \\
\hline Total & 282.90 & 432.63 & 1339.20 & 694.07 & \\
\hline Risperidone & 152.10 & 252.61 & 902.40 & 239.06 & \\
\hline Olanzapine & 363.90 & 515.45 & * & $*$ & \\
\hline Paliperidone & 930.60 & 409.65 & 1466.10 & 753.56 & $<.0001$ \\
\hline Stable & 315.00 & 402.88 & 1296.00 & 710.30 & \\
\hline Risperidone & 160.20 & 183.22 & 1180.80 & 224.10 & \\
\hline Olanzapine & 408.90 & 490.39 & * & $*$ & \\
\hline Paliperidone & 1080.00 & 680.32 & 1315.80 & 767.59 & $<.0001$ \\
\hline Switch & 312.00 & 549.40 & 1504.20 & 739.71 & \\
\hline Risperidone & 162.90 & 180.08 & 616.50 & 190.51 & \\
\hline Olanzapine & 348.00 & 656.16 & * & $*$ & \\
\hline Paliperidone & 701.70 & 392.30 & 1760.40 & 569.60 & $<.0001$ \\
\hline Relapse & 65.40 & 180.08 & * & $*$ & \\
\hline Risperidone & 42.90 & 134.22 & * & $*$ & \\
\hline Olanzapine & 69.00 & 65.97 & $*$ & $*$ & \\
\hline Paliperidone & * & $*$ & $*$ & $*$ & \\
\hline
\end{tabular}


Supplementary Table 1. Currently available LAI atypical antipsychotics

\begin{tabular}{|c|c|c|c|}
\hline Proprietary Name & Generic Name & Release to Market & Dosage \\
\hline Abilify Maintena & Aripiprazole & March 2013 & $\begin{array}{l}300 \mathrm{mg} / \mathrm{month} \text { (deltoid/gluteal) } \\
400 \mathrm{mg} / \mathrm{month} \text { (deltoid/gluteal) }\end{array}$ \\
\hline Aristada & Aripiprazole & October 2015 & $\begin{array}{l}441 \mathrm{mg} / \mathrm{month} \text { (deltoid/gluteal) } \\
662 \mathrm{mg} / \mathrm{month} \text { (gluteal) } \\
882 \mathrm{mg} / \mathrm{month} \text { or } 6 \text { weeks (gluteal) } \\
1064 \mathrm{mg} / 2 \text { months (gluteal) }\end{array}$ \\
\hline Zyprexa Relprevv & Olanzapine & December 2009 & $\begin{array}{l}105 \mathrm{mg} / 2 \text { weeks (gluteal) } \\
210 \mathrm{mg} / 2 \text { weeks (gluteal) } \\
300 \mathrm{mg} / 2 \text { or } 4 \text { weeks (gluteal) } \\
405 \mathrm{mg} / 2 \text { or } 4 \text { weeks (gluteal) }\end{array}$ \\
\hline Invega Sustenna & Paliperidone & July 2009 & $\begin{array}{l}39 \mathrm{mg} / \mathrm{month} \text { (deltoid/gluteal) } \\
78 \mathrm{mg} / \mathrm{month} \text { (deltoid/gluteal) } \\
117 \mathrm{mg} / \mathrm{month} \text { (deltoid/gluteal) } \\
156 \mathrm{mg} / \mathrm{month} \text { (deltoid/gluteal) } \\
234 \mathrm{mg} / \mathrm{month} \text { (deltoid/gluteal) }\end{array}$ \\
\hline Invega Trinza & Paliperidone & May 2015 & $\begin{array}{l}273 \mathrm{mg} / 3 \text { months (deltoid/gluteal) } \\
410 \mathrm{mg} / 3 \mathrm{months} \text { (deltoid/gluteal) } \\
546 \mathrm{mg} / 3 \mathrm{months} \text { (deltoid/gluteal) } \\
819 \mathrm{mg} / 3 \mathrm{months} \text { (deltoid/gluteal) }\end{array}$ \\
\hline Risperdal Consta & Risperidone & October 2003 & $\begin{array}{l}12.5 \mathrm{mg} / 2 \text { weeks (deltoid/gluteal) } \\
25 \mathrm{mg} / 2 \text { weeks (deltoid/gluteal) } \\
37.5 \mathrm{mg} / 2 \text { weeks (deltoid/gluteal) } \\
50 \mathrm{mg} / 2 \text { weeks (deltoid/gluteal) }\end{array}$ \\
\hline Perseris Kit & Risperidone & August 2018 & $\begin{array}{l}\text { 90mg/month (SC abdominal) } \\
120 \mathrm{mg} / \mathrm{month}(\mathrm{SC} \text { abdominal })\end{array}$ \\
\hline
\end{tabular}

SC: Subcutaneous

Information obtained from www.fda.gov41 and package inserts 
Figure 1. Study sample selection flow chart

8,899 All patients with an inpatient schizophrenia diagnosis in 20102015
3,587 Excluded patients without an inpatient diagnosis during index period $1 / 1 / 12-11 / 21 / 14$

1,102 Excluded patients who were not within age 18-64 years on index hospitalization

4,210 Patients with schizophrenia who meet age criteria with an index hospitalization

2,926 Patients with schizophrenia who meet age criteria during index period with enrollment for 24 months prior

1,600 Continuously enrolled patients with schizophrenia in index, pre-index, \& who matched age criteria

631 Continuously enrolled patients with schizophrenia in index, preindex, \& who matched age and prior hospitalization criteria
1,284 Excluded patients without enrollment 24 months prior to index date
1,326 Excluded patients without enrollment 405 days after index hospitalization
969 Excluded patients without at least 2 schizophrenia hospitalizations during pre-index period
448 Excluded patients without an SGA or LAI prescription within 40 days of index discharge or with a LAI prescription before index and with extensive inpatient use on index, 60+ days

183 Continuously enrolled patients with schizophrenia in index and preindex period. Matched age/prior hospitalization criteria, are prescribed SGA PO or LAI \& naïve to LAIs
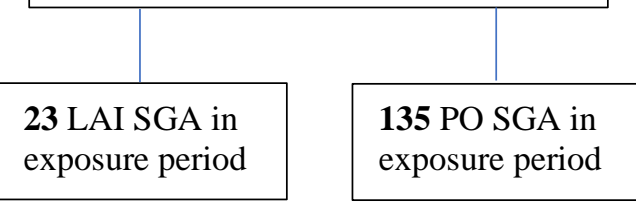

25 PO SGA

patients removed on aripiprazole or who switched to LAI 
Figure 2. Study schematic diagram

\begin{tabular}{|c|c|c|}
\hline $\begin{array}{c}\text { Pre-index Period } \\
\text { (Jan 1 2010-Dec 31 2011) }\end{array}$ & $\begin{array}{c}\text { Index Period } \\
\text { (Jan 1 2012-Nov 21 2014) }\end{array}$ & $\begin{array}{c}\text { Follow-up period } \\
\text { (Jan 1 2012-Dec 31 2015) }\end{array}$ \\
\hline $\begin{array}{c}\text { 24-month pre- } \\
\text { index period }\end{array}$ & $\begin{array}{c}\text { 40-day exposure } \\
\text { period }\end{array}$ \\
\cline { 2 - 2 } $\begin{array}{c}\text { Index Date } \\
\text { Most recent ICD-9 295* } \\
\text { hospitalization in } \\
\text { Jan 1 2012-Nov 21 } \\
\text { 2014 }\end{array}$ \\
\hline
\end{tabular}

- Pre-index: 24 months prior to index date

- Index date: most recent 295 hospitalization during index period

- Exposure period: 40-day exposure window for oral SGA or LAI SGA prescription after index date discharge

- Follow-up: 12 months and 40-days from index date

Figure 3. Decision Tree Diagram

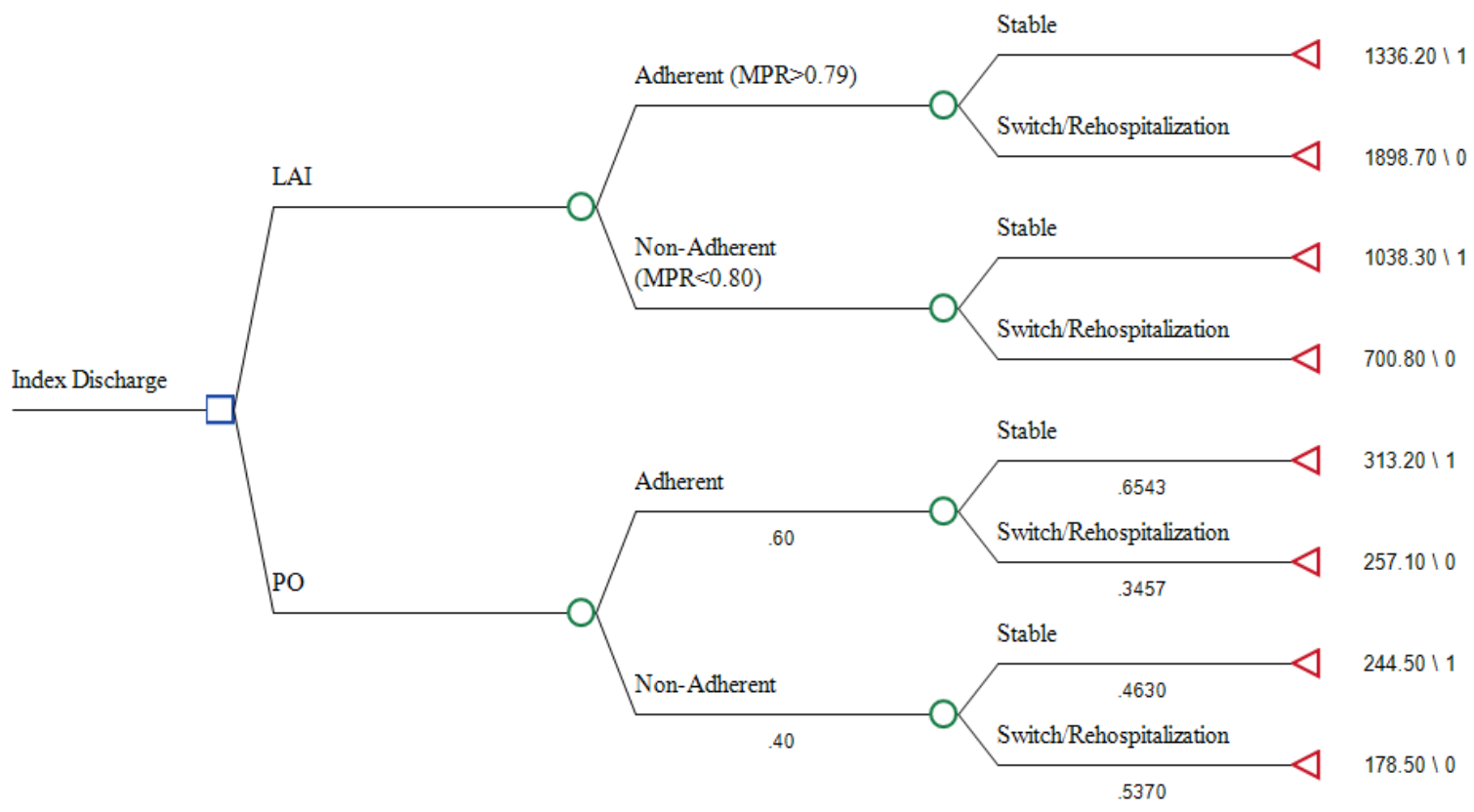


Figure 4. Sensitivity analysis: tornado diagram

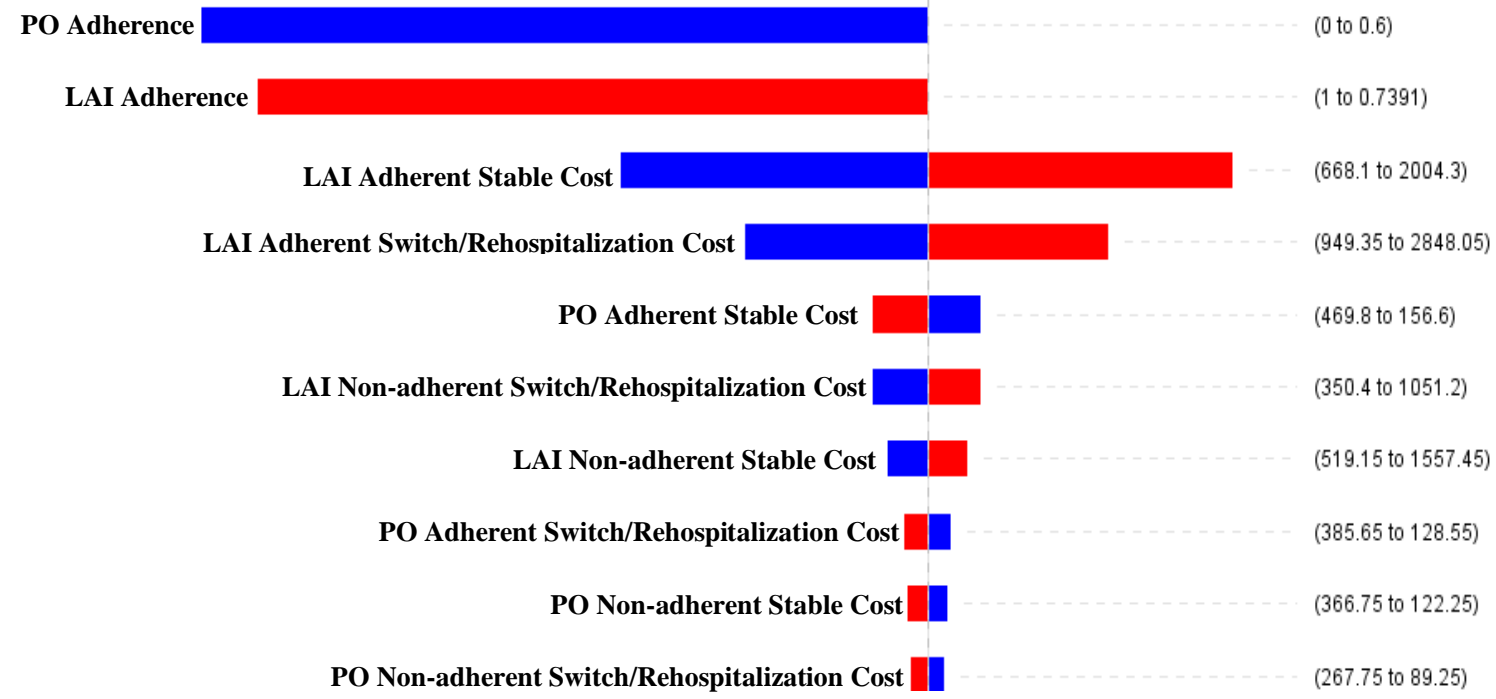

Figure 5. One-way sensitivity analysis: LAI adherence

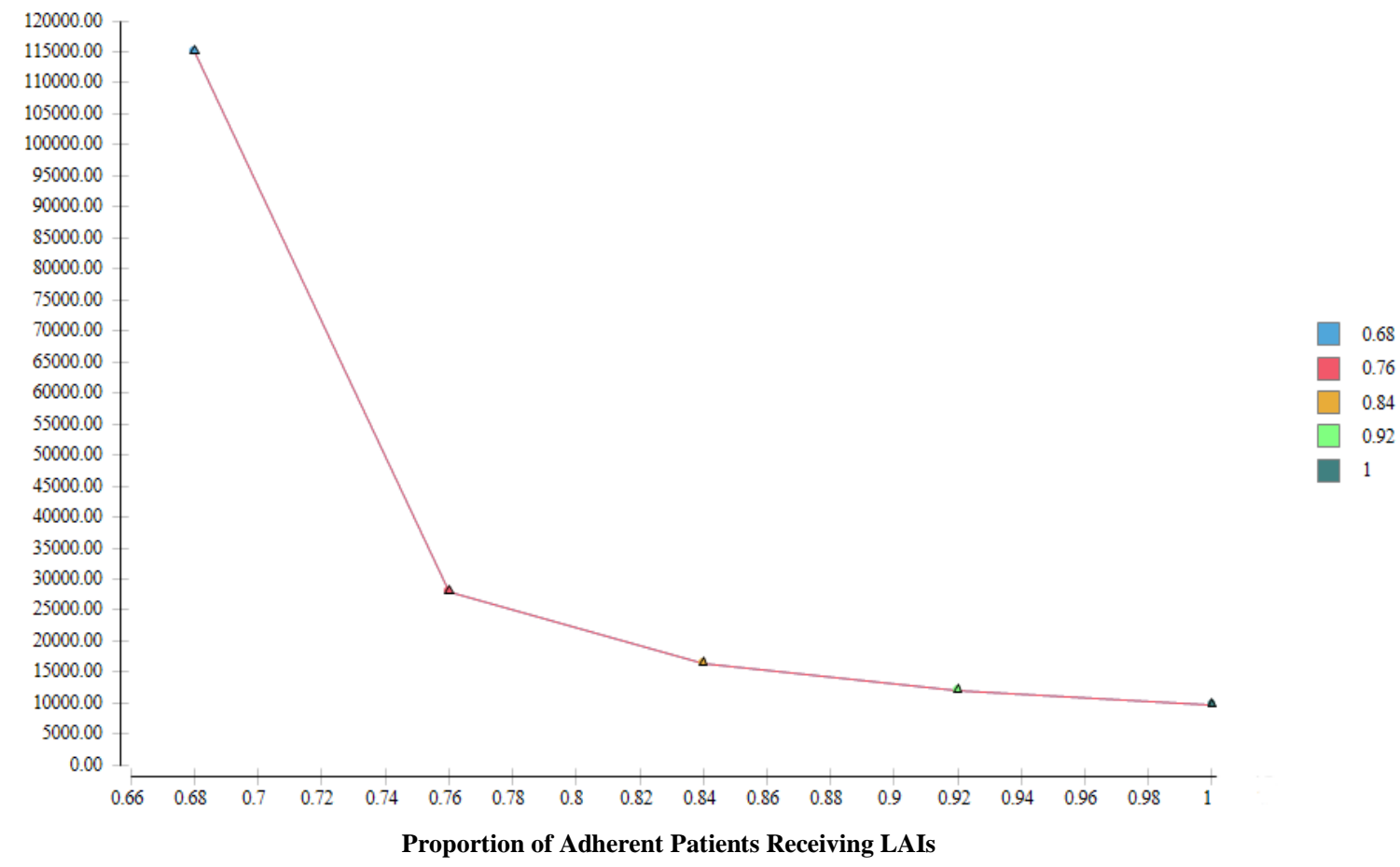




\section{BIBLIOGRAPHY}

1. The National Institute of Mental Health, U.S. Department of Health and Human Services. Health Topics: Schizophrenia. February 2016. Available from: https://www.nimh.nih.gov/health/topics/schizophrenia/index.shtml [Cited December 2019]

2. de Leon J, Diaz FJ. A meta-analysis of worldwide studies demonstrates an association between schizophrenia and tobacco smoking behaviors. Schizophrenia research. 2005;76(2):135-157. doi:10.1016/j.schres.2005.02.010.

3. Van Dorn RA, Desmarais SL, Scott Young M, Sellers BG, Swartz MS. Assessing illicit drug use among adults with schizophrenia. Psychiatry Research. 2012;200(2-3):228-236. doi:10.1016/j.psychres.2012.05.028.

4. Saha S, Chant D, McGrath J. A systematic review of mortality in schizophrenia: is the differential mortality gap worsening over time? Archives of General Psychiatry. 2007;64(10):1123-1131. doi:10.1001/archpsyc.64.10.1123.

5. Olfson M, Gerhard T, Huang C, Crystal S, Stroup TS. Premature mortality among adults with schizophrenia in the united states. JAMA Psychiatry. 2015;72(12):1172-1181. doi:10.1001/jamapsychiatry.2015.1737.

6. Hjorthøj C, Stürup AE, McGrath JJ, Nordentoft M. Years of potential life lost and life expectancy in schizophrenia: a systematic review and meta-analysis. Lancetpsychiatry. 2017;4(4):295-301. doi:10.1016/S2215-0366(17)30078-0.

7. Seeman P. Atypical antipsychotics: mechanism of action. The Canadian Journal of Psychiatry. 2002;47(1):29-40. doi:10.1177/070674370204700106.

8. O'Brien A. Comparing the risk of tardive dyskinesia in older adults with firstgeneration and second-generation antipsychotics: A systematic review and metaanalysis. International Journal of Geriatric Psychiatry. 2016;31(7):68-693. doi:10.1002/gps.4399.

9. Carbon M, Kane JM, Leucht S, Correll CU. Tardive dyskinesia risk with firstand second-generation antipsychotics in comparative randomized controlled trials: a meta-analysis. World Psychiatry : Official Journal of the World Psychiatric Association (WPA). 2018;17(3):330-340. doi:10.1002/wps.20579.

10. Hálfdánarson Ó, Zoëga H, Aagaard L, Bernardo M, Brandt L, Fusté AC, et al. International trends in antipsychotic use: a study in 16 countries, 2005-2014. European Neuropsychopharmacology. 2017;27(10):1064-1076. doi:10.1016/j.euroneuro.2017.07.001. 
11. Heslin KC (AHRQ), Elixhauser A (AHRQ), Steiner CA (AHRQ). Hospitalizations Involving Mental and Substance Use Disorders Among Adults, 2012. HCUP Statistical Brief \#191. June 2015. Agency for Healthcare Research and Quality, Rockville, MD. Available from: https://www.hcupus.ahrq.gov/reports/statbriefs/sb191-Hospitalization-Mental-Substance-UseDisorders-2012.jsp [Cited December 2019]

12. McDermott KW (IBM Watson Health), Elixhauser A (AHRQ), Sun R (AHRQ). Trends in Hospital Inpatient Stays in the United States, 2005-2014. HCUP Statistical Brief \#225. June 2017. Agency for Healthcare Research and Quality, Rockville, MD. Available from: https://www.hcupus.ahrq.gov/reports/statbriefs/sb225-Inpatient-US-Stays-Trends.jsp [Cited December 2019]

13. Torio C (AHRQ), Moore B (Truven Health Analytics). National Inpatient Hospital Costs: The Most Expensive Conditions by Payer, 2013. HCUP Statistical Brief \#204. May 2016. Agency for Healthcare Research and Quality, Rockville, MD. Available from: https://www.hcup-us.ahrq.gov/reports/statbriefs/sb204Most-Expensive-Hospital-Conditions.jsp [Cited December 2019]

14. Cloutier M, Aigbogun MS, Guerin A, Nitulescu R, Ramanakumar AV, Kamat SA, et al. The economic burden of schizophrenia in the united states in 2013. The Journal of Clinical Psychiatry. 2016;77(6):764-771. doi:10.4088/JCP.15m10278.

15. Almond S, Knapp M, Francois C, Toumi M, Brugha T. Relapse in schizophrenia: costs, clinical outcomes and quality of life. British Journal of Psychiatry. 2004;184(4):346-351. doi:10.1192/bjp.184.4.346.

16. Ascher-Svanum H, Zhu B, Faries DE, Salkever D, Slade EP, Xiaomei P, et al. The cost of relapse and the predictors of relapse in the treatment of schizophrenia. BMC Psychiatry. 2010;10(1). doi:10.1186/1471-244x-10-2.

17. Viguera AC, Baldessarini RJ, Hegarty JD, van Kammen DP, Tohen M. Clinical risk following abrupt and gradual withdrawal of maintenance neuroleptic treatment. Archives of General Psychiatry. 1997;54(1):49-55. doi:10.1001/archpsyc.1997.01830130055011.

18. Alvarez-Jimenez M, Priede A, Hetrick SE, Bendall S, Killackey E, Parker AG, et al. Risk factors for relapse following treatment for first episode psychosis: a systematic review and meta-analysis of longitudinal studies. Schizophrenia Research. 2012;139(1-3):116-128. doi:10.1016/j.schres.2012.05.007.

19. Valenstein M, Ganoczy D, McCarthy JF, Myra Kim H, Lee TA, Blow FC. Antipsychotic adherence over time among patients receiving treatment for schizophrenia: a retrospective review. The Journal of Clinical Psychiatry. 2006;67(10):1542-1550. doi:10.4088/jcp.v67n1008. 
20. Lacro, J. P., Dunn, L. B., Dolder, C. R., Leckband, S. G., \& Jeste, D. V. Prevalence of and risk factors for medication nonadherence in patients with schizophrenia: A comprehensive review of recent literature. The Journal of Clinical Psychiatry, 2002;63(10):892-909. doi:10.4088/jcp.v63n1007.

21. Zhang W, Amos TB, Gutkin SW, Lodowski N, Giegerich E, Joshi K. A systematic literature review of the clinical and health economic burden of schizophrenia in privately insured patients in the united states. Clinicoeconomics and Outcomes Research : CEOR. 2018;10:309-320. doi:10.2147/CEOR.S156308.

22. Brissos S, Veguilla MR, Taylor D, Balanzá-Martinez V. The role of long-acting injectable antipsychotics in schizophrenia: a critical appraisal. Therapeutic Advances in Psychopharmacology. 2014;4(5):198-219. doi:10.1177/2045125314540297.

23. Gaebel W, Schreiner A, Bergmans P, de Arce R, Rouillon F, Cordes J, et al. Relapse prevention in schizophrenia and schizoaffective disorder with risperidone long-acting injectable vs quetiapine: results of a long-term, open-label, randomized clinical trial. Neuropsychopharmacology. 2010;35(12):2367-77. doi:10.1038/npp.2010.111.

24. Leucht C, Heres S, Kane JM, Kissling W, Davis JM, Leucht S. Oral versus depot antipsychotic drugs for schizophrenia- a critical systematic review and metaanalysis of randomised long-term trials. Schizophrenia Research. 2011;127(13):83-92. doi:10.1016/j.schres.2010.11.020.

25. Einarson TR, Maia-Lopes S, Goswami P, Bereza BG, Van Impe K. Economic analysis of paliperidone long-acting injectable for chronic schizophrenia in Portugal. Journal of Medical Economics. 2016;19(9):913-921. doi:10.1080/13696998.2016.1184156.

26. Furiak NM, Ascher-Svanum H, Klein RW, Smolen LJ, Lawson AH, Montgomery $\mathrm{W}$, et al. Cost-effectiveness of olanzapine long-acting injection in the treatment of patients with schizophrenia in the united states: a micro-simulation economic decision model. Current Medical Research \& Opinion. 2011;27(4):713-730. doi:10.1185/03007995.2011.554533.

27. Heres S, Hamann J, Kissling W, Leucht S. Attitudes of psychiatrists toward antipsychotic depot medication. The Journal of Clinical Psychiatry. 2006;67(12):1948-1953. doi:10.4088/jcp.v67n1216.

28. Basu A, Benson C, Alphs L. Projecting the Potential Effect of Using Paliperidone Palmitate Once-Monthly and Once-Every-3-Months Long-Acting Injections Among Medicaid Beneficiaries with Schizophrenia. Journal of Managed Care \& Specialty Pharmacy. 2018;24(8):759-768. doi:10.18553/jmcp.2018.24.8.759. 
29. Optum Clinformatics Data Mart. 2014. Optum, Inc.

30. Gibson PJ, Damler R, Jackson EA, Wilder T, Ramsey JL. The Impact of Olanzapine, Risperidone, or Haloperidol on the Cost of Schizophrenia Care in a Medicaid Population. Value in Health. 2004;7(1):22-35. doi:10.1111/j.15244733.2004.71272.x.

31. Song X, El Khoury AC, Brouillette M, Smith D, Joshi K. Treatment discontinuation of long-acting injectables or oral atypical antipsychotics among Medicaid recipients with schizophrenia. Journal of Medical Economics. 2019; 22(11):1105-1112. doi:10.1080/13696998.2019.1615927.

32. Marcus SC, Zummo J, Pettit AR, Stoddard J, Doshi JA. Antipsychotic Adherence and Rehospitalization in Schizophrenia Patients Receiving Oral Versus LongActing Injectable Antipsychotics Following Hospital Discharge. Journal of Managed Care \& Specialty Pharmacy, 2015; 21(9);754-769. doi:10.18553/jmcp.2015.21.9.754.f.

33. Yu AP, Atanasov P, Ben-Hamadi R, Birnbaum H, Stensland MD, Philips G. Resource Utilization and Costs of Schizophrenia Patients Treated with Olanzapine versus Quetiapine in a Medicaid Population. Value in Health. 2009;12(5):708-715. doi:10.1111/j.1524-4733.2008.00498.x.

34. TreeAge Pro 2018, R1. TreeAge Software, Williamstown, MA; Available from: http://www.treeage.com [Cited December 2019]

35. Lehman AF, Lieberman JA, Dixon LB, McGlashen TH, Miller AL, Perkins DO, et al. Practice guideline for the treatment of patients with schizophrenia, second edition. The American Journal of Psychiatry. 2004;161(2):1-56.

36. Institute for Clinical and Economic Review. ICER Value Framework. Value Assessment. February 13, 2017. Available from: https://icer-review.org/wpcontent/uploads/2016/02/ICER-Value-Assessment-Proposed-Updates-Webinar021317.pdf [Cited December 2019]

37. Barnett PG, Scott JY, Krystal JH, Rosenheck RA. Cost and Cost-Effectiveness in a Randomized Trial of Long-Acting Risperidone for Schizophrenia. The Journal of Clinical Psychiatry. 2012;73(05):696-702. doi:10.4088/jcp.11m07070.

38. Lieberman JA, Stroup TS, McEvoy JP, Swartz MS, Rosenheck RA, Perkins DO, et al. Effectiveness of antipsychotic drugs in patients with chronic schizophrenia. New England Journal of Medicine. 2005;353(12):1209-23. doi:10.1056/NEJMoa051688. 
39. Offord S, Wong B, Mirski D, Baker RA, Lin J. Healthcare resource usage of schizophrenia patients initiating long-acting injectable antipsychotics vs. oral. Journal of Medical Economics. 2013;16(2):231-39. doi:10.3111/13696998.2012.751025.

40. Nuhoho S, Saad A, Saumell G, Ribes D, El Khoury AC. Economic evaluation of paliperidone palmitate once monthly for treating chronic schizophrenia patients in the United Arab Emirates. Current Medical Research and Opinion. 2018;34(4):601-611. doi:10.1080/03007995.2017.1417246.

41. US Food and Drug Administration. October 2019. https://www.fda.gov/ [Cited December 2019] 